\title{
A STUDY OF HISTOCYTOLOGICAL FINDINGS OF LUNG LESIONS IN IMAGE GUIDED FNAC AND BIOPSY IN TERTIARY CARE CENTRE
}

\section{Pathology}

Dr. Renuka Gahine Director, Professor and Head of the Department, Department of Pathology, Pt. J.N.M. Medical College and Dr. B.R.A.M. Hospital, Raipur (C.G.)

Dr (Mrs.) Assistant Professor, Department of Pathology, Pt. J.N.M. Medical College and Dr. Shashikala Kosam B.R.A.M. Hospital, Raipur(C.G.)

Dr Vivek Patre

Professor, Department of Radiology, Pt. J.N.M. Medical College and Dr. B.R.A.M. Hospital, Raipur(C.G.)

\section{Dr Kiranlata Bhagat*}

Postgraduate student, Department of Pathology, Pt. J.N.M. Medical College and Dr. B.R.A.M. Hospital, Raipur (C.G.) *Corresponding Author

\section{ABSTRACT}

Aims and Objectives: To study the cytological and histological findings of lung masses and correlate findings with clinical and radiological findings.

Material and methods: The study was an observational study, comprised of two years of prospective from December 2017 to September 2019 and five years of retrospective study between October 2012 to November 2017, conducted in Histopathology \& Cytology laboratory, Department of Pathology, Pt. J.N.M. Medical College \& Dr. B.R.A.M. Hospital, Raipur, (C.G.), a tertiary referral center.

Result: Total 104 cases were studied . Out of 104 lung lesions 74 (71.2\%) were males and 30 (28.8\%) were females with M:F of 2.46:1. Majority of lung lesions were seen in the age group of 61-70 years i.e. 35 (33.66\%) and 51-60 years i.e. 30 (28.85\%) followed by $41-50$ years 17 (16.35\%). Mean age of the patients in our study was 56.4 years. Smoking was the most common predisposing factor for lung carcinoma observed in 58 $(55.77 \%)$ cases followed by tobacco chewing. Clinically the most common complaint was cough in 65 (62.5\%) cases, followed by weight loss. 10 cases were diagnosed as benign and 94 cases as malignant. Among benign lesions most common lung lesions were non-specific inflammatory lesions reported in $6(5.77 \%)$ cases followed by granulomatous lesion in $3(2.89 \%)$, hydatid cyst in $2(1.93 \%)$ and aspergilloma in $1(0.97 \%)$ case. Adenocarcinoma was the most common malignant lung lesion found in $52(50 \%)$ cases followed by Squamous cell carcinoma 20 (24\%), Small cell carcinoma $12(13.04 \%)$ and Poorly differentiated carcinoma $6(5.77 \%)$ cases. The sensitivity, specificity, positive predictive value, negative predictive value and accuracy of our study was $97.83 \%, 66.67 \%, 95.74 \%, 80.0 \%$ and $94.23 \%$ respectively.

Conclusion: Guided FNAC and biopsy are safe, simple, less invasive, cost effective, well accepted and accurate diagnostic procedures with minimal complications and low morbidity rates.

\section{KEYWORDS}

lung carcinoma, CT guided FNAC, Biopsy, histo-cytological correlation.

\section{INTRODUCTION}

Lung cancer is the most commonly diagnosed malignancy across worldwide and also the most common cause of cancer related death in men and second most common in women worldwide ${ }^{[1]}$, with an average 5 year survival rate ${ }^{[2]}$. There are various histological cell type of lung carcinoma like squamous cell carcinoma, adenocarcinoma, small cell carcinoma, pleuropulmonary blastoma and bronchoalveolar carcinoma.

Image guided Fine needle aspiration cytology (FNAC) and biopsy are rapid, sensitive and inexpensive procedures for diagnosing lung lesions. Imaging studies play a key role in the detection, staging and post treatment follow up of patients with lung masses. CT scan is the standard imaging modality used for the evaluation of lung masses ${ }^{[3]}$. FNAC was first used by Martin and Ellis as a diagnostic tool ${ }^{[4]}$.

FNAC and biopsy of lung can be performed under the guidance of radiological imaging ${ }^{[5,6]}$. The role of FNAC and biopsy is predominantly to differentiate between benign and malignant lesion.

Contraindication of CT guided FNAC and biopsies of lung are breathlessness, uncontrolled cough, bleeding disorders, pulmonary arterial hypertension and suspected hydatid cyst ${ }^{[7]}$, including patients undergoing anticoagulant therapy ${ }^{[8]}$. In case of hydatid cyst mostly authors do not advice for the FNAC and biopsy due to possibility of anaphylactic reaction due to leaking cyst fluid or implantation of germinal epithelium ${ }^{[9,10]}$.

Accordingly, this study had been carried out with an aim to study the cytologic pattern of lung masses and correlate the findings with clinical and radiological findings.

\section{MATERIALAND METHODS}

The study was observational study, comprised of 104 cases, 61 prospective and 43 retrospective conducted in Histopathology \& Cytology laboratory, Department of Pathology, Pt. J.N.M. Medical
College \& Dr. B.R.A.M. Hospital, Raipur, (C.G.), a tertiary referral center. Prospectively from December 2017 to September 2019 and retrospective study duration was between October 2012 to November 2017. All the patients having lung masses or lesions in the lung attending medical, surgical, chest and pulmonary medicine both IPD and OPD were included.

All the patients presented with lung masses on the basis of clinical and radiological examinations underwent image guided FNAC and biopsies were included. Patients who are not willing to participate in the study and patients in whom image guided FNAC and biopsy are contraindicated were excluded.

The patients were selected with proper history including bleeding disorders and diabetes mellitus, hypertension, COPD . General and systemic examination done to minimize the intraprocedural complications and rule out any systemic involvement and metastasis. The lung lesion was assessed carefully with the help of radiological scan films either x-ray, CT scan or MRI. With proper aseptic precaution and positioning of the patient, the site was marked, where the lesion was easily approachable through needle. The $10 \%$ lignocaine was applied at the marked site. 22gauge needle (LP needle) with $10 \mathrm{ml}$ attached plastic syringe and biopsy needle was used and FNAC was done and the biopsied tissue was obtained. From the FNAC sample smears were made, for MGG, H \& E and for PAP(Papanicolaou). Tissue biopsy of approximately $1 \mathrm{~cm}$ measurement was fixed in $10 \%$ buffer formalin. The labelled sample was processed in histology and cytology section.

\section{RESULT}

Total 104 cases of lung lesions were studied, out of which 61 cases were prospective and 43 cases were retrospective.

Out of 104 lung lesions 74 (71.2\%) were males and 30 (28.8\%) were females with M:F of 2.46:1. Majority of lung lesions were seen in the age group of $61-70$ years i.e. $35(33.66 \%)$ and $51-60$ years i.e. 30 
$(28.85 \%)$ followed by $41-50$ years $17(16.35 \%)$. Mean age of the patients in our study was 56.4 years.

Smoking was the most common predisposing factor for lung carcinoma observed in $58(55.77 \%)$ cases followed by tobacco chewing $17(16.35 \%)$. Clinically the most common complaint was cough in $65(62.5 \%)$ cases, followed by weight loss $14(13.46 \%)$, chest pain $12(11.53 \%)$, breathlessness $10(9.62 \%)$, hemoptysis $2(1.93 \%)$ and fever in $1(0.96 \%)$ case.

Radiologically lung lesions were commonly observed in left upper lobe in $30(28.84 \%)$ cases and left lower lobe $23(22.12 \%)$ cases, while on the right side lesions were more common in the right upper lobe 27 $(25.97 \%)$ cases. Of the total lesions $67(64.43 \%)$ were between $3-7$ $\mathrm{cm}$ in diameter followed by $34(32.69 \%)$ lesions of less than $3 \mathrm{~cm}$ diameter and rest of cases were more than $7 \mathrm{~cm}$ in diameter. Largest lesion found in our study was $12 \mathrm{~cm}$ in diameter. On radiology 10 $(9.62 \%)$ cases were reported as benign and $94(90.38 \%)$ as malignant.

Cytologically, 8 cases were reported as benign, 90 cases as malignant and 6 cases were found inadequate. Among benign lesions, nonspecific inflammatory lesions were seen in $4(3.85 \%)$ cases. Among malignant lesions Adenocarcinoma was the commonest 36 (34.62\%) followed by Squamous cell carcinoma $13(12.5 \%)$, Small cell carcinoma $9(8.66 \%)$ and Poorly differentiated carcinoma $5(4.81 \%)$ cases. Non-small cell carcinoma was reported in $10(9.62 \%)$, cases that could not be specifically categorized and $12(11.54 \%)$ cases reported as suspicious of malignancy/atypical cells, and 2 cases with metastatic deposits of breast.

Histopathologically, 10 cases were diagnosed as benign and 94 cases as malignant. Among benign lesions most common lung lesions were non-specific inflammatory lesions reported in $6(5.77 \%)$ cases followed by granulomatous lesion in $3(2.89 \%)$, hydatid cyst in 2 $(1.93 \%)$ cases and aspergilloma in $1(0.97 \%)$ case. Adenocarcinoma was the most common malignant lung lesion found in $52(50 \%)$ cases followed by Squamous cell carcinoma 20 (24\%), Small cell carcinoma $12(13.04 \%)$ and Poorly differentiated carcinoma $6(5.77 \%)$ cases. Out of $10 \mathrm{NSCC}$ reported on cytology, 9 were confirmed as Adenocarcinoma and one case as Squamous cell carcinoma on histopathology.

Similarly 12 cases were reported as suspicious of malignancy on cytology were confirmed as adenocarcinoma(5), squamous cell carcinoma(3) and small cell carcinoma(4) respectively on histopathology. Histopathological reports of lung lesions were considered as final and confirmatory, it was correlated with radiological and cytological findings. It was found that concordance of radiological and cytological diagnosis was almost reliable.

The sensitivity, specificity, positive predictive value, negative predictive value and accuracy of our study was $97.83 \%, 66.67 \%$, $95.74 \%, 80.0 \%$ and $94.23 \%$ respectively. The results was found to be statistically significant $(\mathrm{p}$ value $<0.05)$.

Table 1-Gender-wise distribution of benign and malignant lesions on the basis of histopathology

\begin{tabular}{|c|c|c|}
\hline Gender & $\begin{array}{c}\text { Benign lesion } \\
(\mathbf{n}=\mathbf{1 2})\end{array}$ & $\begin{array}{c}\text { Malignant lesion } \\
(\mathbf{n = 9 2})\end{array}$ \\
\hline Male & $10(9.61 \%)$ & $64(61.54 \%)$ \\
\hline Female & $02(1.92 \%)$ & $28(26.92 \%)$ \\
\hline Total & $12(11.53 \%)$ & $92(88.46 \%)$ \\
\hline
\end{tabular}

Table 2-Cytological diagnosis of various lung lesions

\begin{tabular}{|c|c|c|}
\hline Diagnosis & Number (n=8) & Percentage \\
\hline Benign/ Inflammatory lesion & 01 & \\
Suppurative & 03 & $0.96 \%$ \\
Granulomatous & 04 & $3.88 \%$ \\
Non-specific lesion & $(n=90)$ & \\
\hline Malignant & 16 & 15.39 \\
\hline SqCC & 36 & $34.62 \%$ \\
\hline ADC & 09 & $8.66 \%$ \\
\hline SCC & 10 & $9.62 \%$ \\
\hline NSCC & 05 & $4.81 \%$ \\
\hline PDC & 12 & $11.54 \%$ \\
\hline SOM/ Atypical cells & 02 & $1.91 \%$ \\
\hline Metastasis & 06 & $5.76 \%$ \\
\hline Inadequate & 104 & \\
\hline Total &
\end{tabular}

54 International Journal of Scientific Research
(SqCC- Squamous cell carcinoma; ADC-Adenocarcinoma; SCCSmall cell carcinoma ; NSCC- Non small cell carcinoma; PDC- Poorly differentiated carcinoma; SOM-Suspicious of malignancy)

Table 3-Histopathological Diagnosis of Various Lung Lesions

\begin{tabular}{|l|c|c|}
\hline \multicolumn{1}{|c|}{ Benign lesion } & $\begin{array}{c}\text { Number } \\
(\mathbf{n}=\mathbf{1 2})\end{array}$ & Percentage \\
\hline $\begin{array}{l}\text { Inflammatory- } \\
\text { - Aspergilloma }\end{array}$ & 1 & \\
- Granulomatous inflammation & 3 & $0.97 \%$ \\
- NSIL & $\mathbf{6}$ & $2.89 \%$ \\
Hydatid cyst & 2 & $\mathbf{5 . 7 7 \%}$ \\
\hline Malignant lesion & $(\mathrm{n}=92)$ & $88.93 \%$ \\
\hline SqCC & 20 & $19.24 \%$ \\
\hline ADC & $\mathbf{5 2}$ & $\mathbf{5 0 \%}$ \\
\hline SCC & 12 & $13.04 \%$ \\
\hline PDC & 06 & $5.76 \%$ \\
\hline Metastasis & 02 & $1.93 \%$ \\
\hline Total & 104 & \\
\hline
\end{tabular}

(SqCC- Squamous cell carcinoma; ADC-Adenocarcinoma; SCCSmall cell carcinoma ; NSCC- Non small cell carcinoma; PDC- Poorly differentiated carcinoma;NSIL-Non specific Inflammatory lesion)

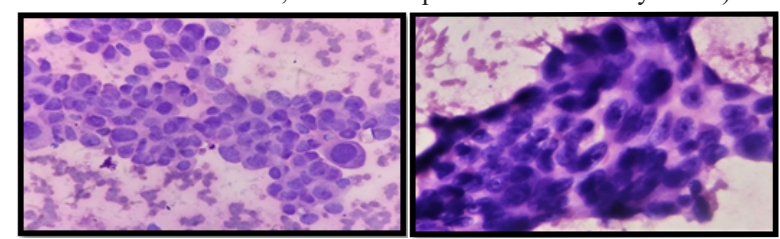

a.

b.

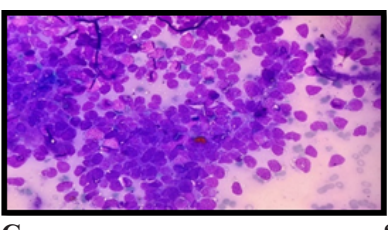

S.

Figure 1- Photomicrograph Cytology: a) Adenocarcinoma- Malignant cells arranged in glandular pattern with eccentrically placed nuclei, (MGG, 400X). b) Squamous cell carcinoma. ill defined cell membrane with high N/C (nuclear cytoplasmic ratio), having, hyper chromatic, clumped chromatin with prominent nucleoli, (H\&E,400X). (c) small cell carcinoma. clusters of Malignant cells showing nuclear moulding,(MGG, 400X).

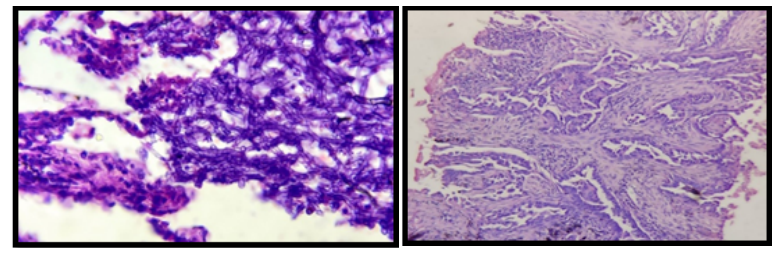

a.

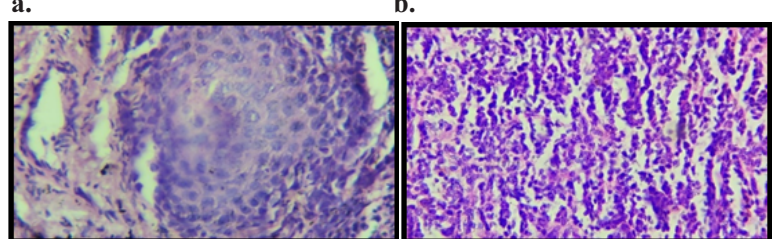

c.

Figure2.- Photomicrograph trucut biopsy(H\&E, 400X). -a) branching septate hyphae. b) Adenocarcinoma. Malignant cells in glandular pattern. (100X). c) Squamous cell carcinoma. d) Small cell carcinoma. Nuclear moulding with dispersed chromatin is seen.

\section{DISCUSSION}

FNAC and biopsy are well established, accurate and safe techniques for the diagnosis of various focal lesions including lung lesions ${ }^{[1]]}$. For further categorization of lung lesions, biopsy is a gold standard procedure. Overall sensitivity for the diagnosis of intrathoracic lung carcinoma is between the range of $70-100 \%{ }^{[12,13,14]}$. Many authors in their studies advised for FNAC in case of strong suspicion of malignancy and the procedure should be performed in the presence of 
Pathologist for proper guidance ${ }^{[1,16]}$. Biopsy have been shown to be more accurate in the specific diagnosis of benign lesions when a CT guided procedure is performed in the absence of a cytopathologist ${ }^{[15,17,18,19]}$. We performed FNAC and biopsy of correspondence patient prospectively.

In the present study on cytology $8(7.69 \%)$ cases were reported as benign and $90(86.53 \%)$ cases as malignant lesions. Among the benign lesions most common was NSIL $4(3.85 \%)$ cases, followed by granulomatous lesions in $3(2.88 \%)$ cases and SL was seen in only 1 case.

Out of the total 90 cases of malignant lesions, adenocarcinoma was the most common lesion reported in $36(34.62 \%)$ cases which was almost similar to the studies of Madan $\mathbf{M}$ et $\mathbf{~ a l}^{20}(30 \%)$, whereas Modi et $\mathbf{a l}^{21}$ (45.71\%), Abrahim et $\mathbf{a l}^{22}(49.2 \%)$, Mondal et $\mathbf{a l}^{23}(52.63 \%)$ and Gangopadhyay et $\mathrm{al}^{24}(54.2 \%)$ reported higher incidence of adenocarcinoma, while Naqvi et $\mathbf{a l}^{\mathbf{2 5}}(20.8 \%)$ reported a lower incidence.

Squamous cell carcinoma was the second most common malignant lesion comprising of $16(15.39 \%)$ cases in our study, which was similar to the study of Madan et $\mathbf{~ a l}^{20}(22.5 \%)$, Mondal et $\mathrm{al}^{23}(22.8 \%)$, Modi et $\mathbf{a l}^{21}(10 \%)$, Kinker et $\mathbf{a l}^{26}(21.43 \%)$, though the incidence rate was variable in these studies. In some of the studies it was the most common lung lesion as reported by Kauli R et $\mathbf{~ a l}^{27}(46.66 \%)$, Rishi et $\mathbf{a l}^{28}(44.44 \%)$, Shrestha et $\mathbf{~ a l}^{29}(39.13 \%)$, Ahmad $\mathbf{Z}$ et al ${ }^{30}(35 \%)$ and MS Hoque et al $^{31}(23.5 \%)$.

Other malignancies reported in our study was Small cell carcinoma in $9(8.66 \%)$ and Poorly differentiated carcinoma in $5(4.81 \%)$ cases. All these cases could not be specifically categorized on cytology and some were reported broadly as non-small cell carcinoma comprising of $9.62 \%$ cases which was similar to the study of Shreshtha et $\mathbf{a l}^{29}$, they reported NSCC in $8.69 \%$ of cases. Some cases were reported as suspicious of malignancy on cytology $12(11.54 \%)$.. On cytology 2 cases of metastatic breast carcinoma were also reported.

FNAC should be performed before tissue biopsy to get a clearer haemorrhage free background and for better cellular yield. However $\mathbf{G}$ Aviram et $\mathbf{~ a l ~}^{11}$ in their study mentioned that FNAC alone is sufficient to achieve an accurate diagnosis in the presence of cytopathologist at the time of procedure, immediately confirming the adequacy of the specimen with unambiguous malignant lesions highlighting the role of cytology in such lesions and for getting an early diagnosis.

We conducted sequential biopsy and FNAC for definitive diagnosis of lung lesion. The most common benign lesion reported in our study was non specific inflammatory lesions in $6(5.77 \%)$ cases followed by 3 $(2.89 \%)$ cases of granulomatous lesion. Hydatid cyst was reported in 2 $(1.93 \%)$ cases in our study which was not clinicoradiologically suspected and was an incidental finding. Very rare case reports are available in literatures of hydatid cyst reported on small biopsy or FNAC, as it is a contraindication to perform such procedures in these cases, else it may lead to severe reactions including anaphylactic shock. Although such complications were not noticed in our cases. Single case of Aspergilloma was also reported.

In our study most common lung lesion reported on histopathology was Adenocarcinoma, in $51(49.03 \%)$ cases followed by Squamous cell carcinoma $20(19.24 \%)$ cases. Of the total cases of adenocarcinoma \& squamous cell carcinoma 10 cases could not be categorized and reported as Non-small cell carcinoma on Cytology. Out of 10 NSCC, 9 were confirmed as $\mathrm{ADC}$ and one case as $\mathrm{SqCC}$ on histopathology.

Similarly 12 cases reported as suspicious of malignancy on cytology were confirmed as adenocarcinoma, squamous cell carcinoma and small cell carcinoma 5, 3 and 4 cases respectively on histopathology. This shows the diagnostic accuracy of histopathology over cytology.

Other lung lesions found on histopathology in present study was Small cell carcinoma $12(13.04 \%)$, Poorly differentiated carcinoma 6 $(5.77 \%)$ and $2(1.92 \%)$ cases of metastasis from breast.

In present study, amongst the benign lesions hydatid cyst was reported on histopathology which was missed on cytology that could be due to faulty technique or chronicity of the lesion. Similarly 10 cases reported as Non-small cell carcinoma and 12 cases as suspicious of malignancy on cytology were rendered definitive diagnosis on histopathology. This emphasizes the role of histopathology in definitive diagnosis and exact categorization and which has many therapeutic implications in the emerging novel and targeted therapies for specific lesions.

The therapeutic advances of non small cell lung carcinoma (NSCLC) that includes tyrosine kinase inhibitors like bevacizumab as first line of therapy in lung Adenocarcinoma with epidermal growth factor receptor mutations is contraindicated in $\mathrm{SqCC}$ as it is associated with life threatening hemorrhage in the later. This implies that it is necessary to precisely classify the NSCLC into Adenocarcinoma and SqCC, so as to undergo targeted therapy.

\section{CONCLUSION}

Guided FNAC and biopsy are safe, simple, less invasive, cost effective, well accepted and accurate diagnostic procedures with minimal complications and low morbidity rates. By limiting the time of FNAC and biopsy combined procedure, complication such as pneumothorax can be minimized. Sequential procedure of guided FNAC and biopsy help in quick diagnosis and appropriate management plan for the patient.

\section{REFERENCES}

International Journal of Research in Medical Sciences Shah D et al. Int J Res Med Sci. 2017 Jun; 5(6):2346-2352.

Surveillance, epidemiology and end results (SEER) statistics fact sheets : Lung and Bronchus by National Cancer Institute.

Stewart BW et al. Word Cancer Report. Lyon, France: International Agency for Research on Cancer. World Health Organization; 2014.

4. Martin HE, Ellis EB. Biopsy by needle puncture and aspiration . Ann Surg. 1930; 169-81. Baselic S, Zukic F ,Milisic S: Percutaneous transthoracic CT guided biopsies of lun lesions; fine needle aspiration biopsy versus core biopsy. Radiol Oncol 2012, 46(1):19-22 Gomez-Macias GS, Guajardo RG, Luna JS, Quintana OB: Inadequate fine needle aspiration biopsy samples; pathologists versus specialists. Cyto Journal 2009, 6:9.

Gia-Khanh Ngu Yen (2008) "Essential of lung tumor cytology “, 2nd edition , surrey $\mathrm{BC}$, Canada, winter.

Svante R. Orell and Gregory F Sterrett's FNAC fifth edition

9. Das DK, Bhambhani S, Pant CS. Ultrasound guided fine needle aspiration cytology: diagnosis of hydatid disease of the abdomen and thorax. Diagn Cytopatho 1995; 12:173-6.

10. Mc Corkell SJ. Unintended percutaneous aspiration of pulmonary echinococcal cysts Am J Roentgenol 1984;143:123-6.

11. G. Aviram et al, Diagnosis of intrathoracic lesions: are sequential fine-needle aspiration (FNA) and core needle biopsy (CNB) combined better than either investigation alone? Clinical Radiology (2007) 62,221e226.

12. Klein JS, Zarka MA. Transthoracic needle biopsy. Radiol Clin North Am 2000;38:235e66.

13. Huanqi L, Boiselle PM, Shepard JA, et al. Diagnostic accuracy and safety of CT-guided percutaneous needle aspiration biopsy of the lung: comparison of small and large nodules. AJR Am J Roentgenol 1996;167:105e9.

14. Arakawa H, Nakajima Y, Kurihara Y, et al. CT-guided transthoracic needle biopsy: a comparison between automated biopsy gun and fine-needle aspiration. Clin Radio $1996 ; 51: 503 \mathrm{e} 6$

15. Austin JM, Cohen MB. Value of having a cytopathologist present during percutaneous fine-needle aspiration biopsy of lung: report of 55 cancer patients and metaanlysis of the literature. AJR Am J Roentgenol 1993;160:175e 7.

16. Santambrogio L, Nosotti M, Bellavitti N, et al. CT-guided fine-needle aspiration cytology of solitary pulmonary nodules. Chest 1997;112:423e5.

17. Greif J, Marmur S, Schwarz Y, et al. Percutaneous core needle biopsy versus fine needle aspiration in the diagnosis of benign lung lesions. Acta Cytol 1999;43:756e60.

18. Laurent F, Latrabe V, Vergier B, et al. Percutaneous CT-guided biopsy of the lung: comparison between aspiration and automated cutting needles using a coaxial technique. Cardiovasc Intervent Radiol 2000;23:266e 72.

19. Lucidarme O, Howarth N, Finet JF, et al. Intrapulmonary lesions: percutaneous automated biopsy with a detachable 18-gauge coaxial cutting needle. Radiology 1998;207: 759e65.

20. Madan et al, Evaluation of Fine Needle Aspiration Cytology in the Diagnosis of Lung Lesion. Cilt/Vol. 26, No. 1,2010; Sayfa, Turkish journal of Pathology.

21. Mitul B et al, Role of FNAC in Lung Carcinoma and its Histo-Cytological Correlation, J Lung Pulm Respir Res 2016, 3(4): 00090

22. Annie E Abrahim et al Image-guided Fine Needle Aspiration Cytology of Intrathoracic Lesions Journal of Cytology ' Volume 36 ' Issue 2! April-June 20

23. Mondal SK et al, Nag D, Das R, Palash M, Pranab B, Manish O. Computed tomogram guided fine-needle aspiration cytology of lung mass with histological correlation: A study in Eastern India.(Mini Symposium - FNAC versus Core Biopsy: Original Article)(Report). S Asian J Cancer 2013:2:14.

24. Gangopadhy et al, Computed tomography guided fine needle aspiration cytology of mass lesions of lung: Our experience Indian J Med Paediatr Oncol. 2011 Oct-Dec; 32(4) 192-196. doi: 10.4103/0971-5851.95139

25. Naqvi et al. Spectrum of intra-thoracic lesion detected by computed tomography guided fine needle aspiration biopsy International Archives of Medicine 2013, 6:4

26. Adya Kinkar Panda et al, Correlation of CT Findings of Thoracic Mass Lesions with CT Guided Aspiration Cytology. National Journal of Laboratory Medicine. 2017 Oct, Vol6(4): PO01-PO05

27. Reena Kouli et al, Percutaneous Ct Guided FNAC Of Lung Masses: Experience At A Tertiary Medical Centre. J. Evolution Med. Dent. Sci./e ISSN- 2278-4802, p ISSN2278-4748/Vol. 05/Issue 34/Apr. 28, 2016

28. Sharma RK et al, Comparative study of computed tomography guided fine needle aspiration cytology and trucut biopsy in diagnosis of lung cancer: a report of 81 cases International Journal of Research in Medical Sciences Sharma RK et al. Int J Res Med Sci. 2016 Mar;4(3):806-808 www.msjonline.org

29. M Shreshtha et al, Evaluation of intrathoracic lesions by image guided fine needle aspiration cytology. Journal of Pathology of Nepal (2019) Vol. 9, 1464-1468.

30. Ahmad Z et al, CT Guided FNAC of Lung Mass - A Retrospective Study of Disease Spectrum, Journal of Histopathology and Cytopathology, 2018 Jul; 2 (2):109-113]

31. MS Hoque et al. Role of CT scan in the Evaluation of Lung Tumor with Cytopathilogical Correlation., Vol. 9, No. 1, January 2014;9(1):37-41 